\title{
How Do We Treat Patients with Hepatitis C Virus Associated-glomerulonephritis?
}

Key words: MPGN, interferon alpha, cryoglobulinemia

It is well known that extrahepatic manifestations often occur in hepatitis $\mathrm{C}$ virus (HCV) infection. Johnson et al first described 8 patients with membranoproliferative glomerulonephritis (MPGN) and HCV infection (1). Most of the cases showed nephrotic syndrome, hypocomplementemia, serum IgM rheumatoid factor and cryoglobulinemia. Although the mechanism by which $\mathrm{HCV}$ induces MPGN has not been known, cryoglobulin containing $\mathrm{HCV}$, anti-HCV antibody and IgM rheumatoid factor may play an important role as an immune complex.

The question is how to treat this disease. Interferon alpha has been approved for treatment of chronic HCV infection. Interferon alpha has been used by several investigators to remove $\mathrm{HCV}$ as an antigen in $\mathrm{HCV}$-associated glomerulonephritis. In a prospective randomized, controlled trial, Misiani et al (2) studied the effect of interferon alpha in 53 patients with $\mathrm{HCV}$-associated cryoglobulinemia. A group of 27 patients received recombinant interferon alfa thrice weekly at a dose of 1.5-3.0 million units for 24 weeks. Serum HCV RNA turned undetectable in 15 of 25 patients $(60 \%)$ who completed the therapy, but in none of the controls. In contrast to the control group, the 15 patients with undetectable levels of HCV RNA in serum had significant improvement in clinical manifestations with decreased serum creatinine levels and urinary protein excretion. However, after the cessation of interferon therapy, all of those who had responded to the therapy showed recurrence. Johnson et al also reported the efficacy of interferon alpha in HCV-associated glomerulonephritis (3). Fourteen patients received interferon alpha at the dose of 3 million units thrice a week for 6-12 months with a significant reduction in proteinuria but no improvement in renal function. A good clinical response was correlated with disappearance of HCV RNA from serum during the treatment. However, relapse of viremia and renal disease was common after completing the therapy. Since then many reports including the effect of highdose interferon (4), ribavirin (5), which is a nucleoside analogue with activity against viruses, and a combination with interferon and ribavirin (6) have been published, and the results were inconsistent. The side effects of interferon alpha are dose dependent and are more frequent with increased duration of therapy. Interferon alpha may also induce renal injury (7). Thus, the optimal dose and duration of interferon therapy in
$\mathrm{HCV}$-associated glomerulonephritis have not been established.

Another therapeutic strategy is to manipulate the immune mechanisms by using corticosteroids, immunosuppresive agents and plasmapheresis. In a randomized controlled study, Dammacco et al (8) compared the treatment outcome among patients treated with either interferon alpha or prednisolone alone, or in combination. While a complete response was achieved in 8 of $15(53.3 \%)$ patients treated with interferon alpha and in 9 of 17 (52.9\%) treated with interferon alpha plus prednisolone, it was found in only 3 of $18(16.7 \%)$ patients who received prednisolone only and in 1 of $15(6.7 \%)$ untreated controls. In the 3 patients in the prednisolone group, improvement of clinical manifestations was observed without significant changes in HCV RNA levels. In contrast, in 5 of 13 (38.5\%) HCV RNA-positive non-responsive patients, a significant increment of HCV RNA levels was demonstrated. Quigg et al reported a case of membranoproliferative glomerulonephritis with cryoglobulinemia and HCV infection (9). In that case cyclophosphamide was very effective and within 1 month of initiating therapy, the patient's cryoglobulin became undetectable in serum. After 3 months the patient's renal function became normal, although serum levels of HCV RNA increased. Komatsuda et al reported the effectiveness and safety of corticosteroids in HCV-associated nephropathy (10). They treated 16 patients with various types of glomerulonephritis and $\mathrm{HCV}$ infection with interferon alpha or corticosteroids. Five patients were treated with interferon alpha without a remarkable effect on renal impairment, whereas 5 of 11 patients treated with steroids showed a decrease in the serum creatinine level and urinary protein excretion. They also described that during the course of steroid therapy, the serum titer of HCV RNA decreased in 5 of 7 patients and aggravation of liver function was not observed. Plasmapheresis has also been used for the treatment of mixed cryoglobulinemia. Mori et al describe in this issue of the Journal that the combination of cryofiltration and corticosteroids improved the clinical manifestations, proteinuria and renal function in a patient with HCV-associated glomerulonephritis with a transient decrease of serum HCV RNA levels (11).

See also $\mathrm{p} 564$.

Immunosuppressive therapy may be useful to treat patients who do not show a favorable result or can not tolerate interferon, although it is not certain that immunosuppressive therapy ameliorates the long-term prognosis of this disease. 
Hideaki YAMABE, MD

The Department of Nursing Education, Faculty of Education, Hirosaki University, 1 Bunkyo-cho, Hirosaki 036-8560

\section{References}

1) Johnson RJ, Gretch DR, Yamabe H, et al. Membranoproliferative glomerulonephritis associated with hepatitis $\mathrm{C}$ virus infection. $\mathrm{N}$ Engl $\mathbf{J}$ Med 328: 465-470, 1993.

2) Misiani R, Bellavita $P$, Fenili $D$, et al. Interferon alfa-2a therapy in cryoglobulinemia associated with hepatitis $C$ virus. N Engl J Med 330: 751 756, 1994.

3) Johnson RJ, Gretch DR, Couser WG, et al. Hepatitis C virus-associated glomerulonephritis. Effect of $\alpha$-interferon therapy. Kidney Int 46: 1700$1704,1994$.

4) Yamabe H, Johnson RJ, Gretch DR, et al. Membranoproliferative glomerulonephritis associated with hepatitis $\mathrm{C}$ virus infection responsive to interferon alpha. Am J Kidney Dis 25: 67-69, 1995.

5) Lopes E, Lopes LV, Silva AE. Mixed cryoglobulinemia and membranoproliferative glomerulonephritis associated with hepatitis $\mathrm{C}$ virus infection. Ann Intern Med 125: 781-782, 1996.
6) Misiani R, Bellavita P, Baio P, et al. Successful treatment of HCV-associated cryoglobulinemic glomerulonephritis with a combination of interferon-alpha and ribavirin. Nephrol Dial Transplant 14: 1558-1560, 1999.

7) Ohta S, Yokoyama H, Wada T, et al. Exacerbation of glomerulonephritis in subjects with chronic hepatitis $C$ virus infection after interferon therapy. Am J Kidney Dis 33: 1040-1048, 1999.

8) Dammacco F, Sansonno D, Han JH, et al. Natural interferon alpha versus its combination with 6-methyl-prednisolone in the therapy of type II mixed cryoglobulinemia: A long-term, randomized, controlled study. Blood 84: 3336-3343, 1994.

9) Quigg RJ, Brathwaite M, Gardner DF, et al. Successful cyclophosphamide treatment of cryoglobulinemic membranopriliferative glomerulonephritis associated with hepatitis C infection. Am J Kidney Dis 25: 798$800,1995$.

10) Komatsuda $\mathrm{A}$, Imai $\mathrm{H}$, Wakui $\mathrm{H}$, et al. Clinicopathological analysis and therapy in hepatitis $C$ virus-associated nephropathy. Intern Med 35: 529533, 1996.

11) Mori $Y$, Kishimoto N, Imai Y, et al. Cryofiltration and oral corticosteroids provide successful treatment for an elderly patient with cryoglobulinemic glomerulonephritis associated with hepatitis $\mathrm{C}$ virus infection. Intern Med 39: 564-569, 2000. 